\title{
Arm Wrestling Injuries - A Clinical Study of Inflammations and Fractures
}

\begin{abstract}
Arm wrestling is a popular and traditional sport that was played by showing strength and displaying muscles until it was transformed in our time into a sport with laws and rules that needs to be well prepared and properly organized. In addition, it is considered a dangerous sport as it leads to fractures and trauma in the bones and muscles and tears in the muscles and ligaments.
\end{abstract}

Ali Alfraih

Keywords:- Arm-Wrestling, Ligaments, Trauma.

\section{INTRODUCTION}

Arm wrestling is an exceptionally basic and well known game due to Its moderate nature and incredible intrigue in mainstream society.

Tragically, it very well may be the impetus of genuine breaks which have been accounted for in the pertinent clinical writing. Reports on wounds during arm wrestling are expanding, with breaks of the homers shaft being the most widely recognized in nature. During an arm wrestling match, two competitors face one another, either standing or plunking down, tie hands together and attempt to stick their rivals arm down to determined even plane. These arm twists, consolidated with different variables, are likely the key thought processes in cracks in arm wrestling. A comprehension of these wounds and its instruments is essential to the endeavor of safe practice techniques for this brandishing methodology.

\section{Problem Statement:}

Many people around the world willing to play this sport but the injuries might stop them permanently. Injures can hinder any athlete not only in the field of arm wrestling in any sporting field, but since we are talking about the field of arm wrestling, we will address the injuries that a player suffers from arm wrestling, which are injuries to the tendons, joints and bones. Therefore if the arm-wrestling player is exposed to any of these injuries, it may hinder him and stop him for certain period from training and from participating in the tournaments or normal matches.

Some of these injuries occur during training or during matches, and they are often the result of insufficient knowledge of this sport and how to follow the necessary rules for safety.

So here the problem statement is unprofessional preparation before joining arm wrestling.

\section{Research Objectives:}

This study expected to survey articles that exhibit case reports about arm-wrestling related injuries and fractures.

\section{LITERATURE REVIEW}

In the sport of arm wrestling, there are many injuries, some of which are dangerous and some of them need time to rest in order to recover well.

Such as:

- Spiral fracture Open lower third of reduction humeral shaft.

- Medial epicondyle fracture.

- shoulder injuries

- concussions

Here is some cases about injuries and fractures happened during arm-wrestling games:

Case 1: ( Singapore 1991) a 24 year -old man, while arm-wrestling for less than 20 seconds, heard a crack and felt a sharp pain in his right arm. He was found to have a closed spiral fracture of the lower third of the shaft of his Humers. While in hospital. He developed a right radial nerve paresis. During the subsequent operation, tension of the radial nerve over the proximal fragment was found. No gross signs of interrupted continuity of the nerve were evident during the operation. Post operatively, the fracture united well. The radial nerve palsy gradually improved over a period of twelve months. He was discharged from follow-up thereafter, having gained full range of movement of his right elbow and shoulder, and full recovery from the radial nerve palsy.

$>$ Case 2: (UK, 2000) this patient was an otherwise fit 24 year old chartered surveyor, who was admitted to casualty with a swollen painful right arm. He was a wellbuilt muscular man who had drunk 3 pints of beer before embarking on a one off arm wrestle challenge with an equally built yet taller man (and hence with longer forearms), who regularly arm wrestled. His only medication was Ventolin and betide inhalers for mild asthma.

The patient was in an offensive (winning) position for the first 30 seconds approximately, then the wrestle was restarted because each wrestler wanted to regain a comfortable sitting position. The patient was then in the neutral to defensive position for about ten seconds when he felt his arm give way and crack with excruciating pain while defending at an obtuse angle of about $100^{\circ}$ (where neutral is regarded as $90^{\circ}$ ). 


\section{THEORETICAL FRAMEWORK}

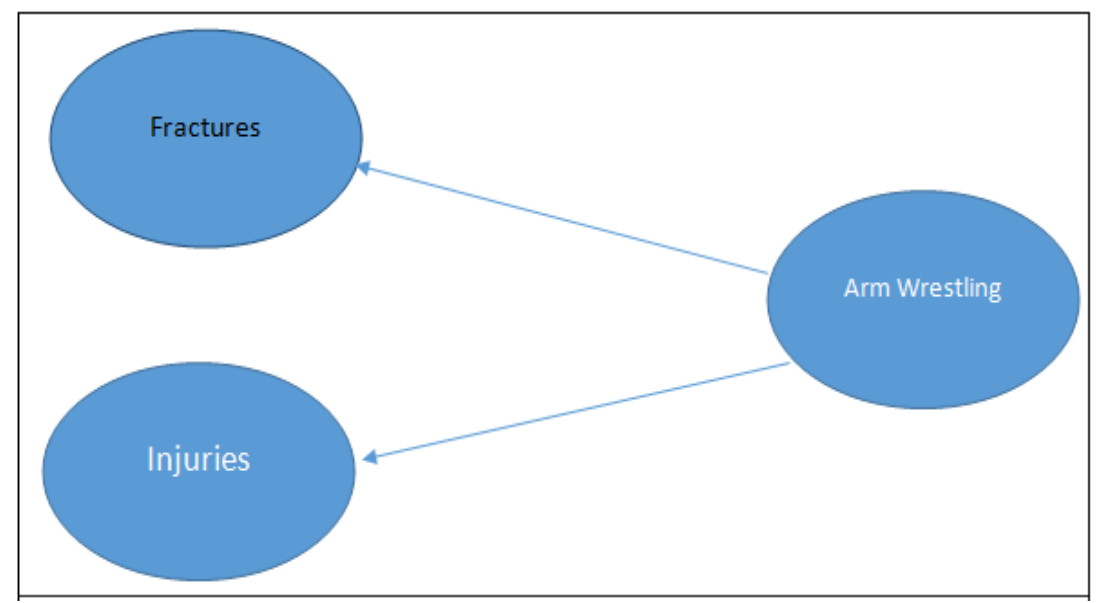

Fig 1

\section{RECOMMENDATION}

Arm wrestling is a popular activity, which ought not to be seen as protected when practiced by beginners, as many reports have demonstrated. Be that as it may, the homogenous idea of the detailed wounds, along with the way that breaks are uncommon.In serious, proficient and directed rivalries, Persuades that right strategy can be an incredible partner in Arm wrestling injury anticipation. All articles explored in this examination expressed that wounds consistently happen when unequal tensional powers straightforwardly influence the homers. By and by, this implies a position when both the arm and lower arm are pivoted, either inside or remotely, in juxtaposition to one another, on a fixed glenoumeral joint. In this manner, competitors, just as normal professionals, ought to be instructed as to evade these negative positions and methods.

\section{FUTURE SCOPE}

We must adhere to some conditions and rules to maintain general safety in the field of arm wrestling. First: Separating professionals and novices in this game to avoid meeting with each other and this leads to a difference in the force pressing on the arm, thus leading to fractures and injuries.

Secondly, to make sure that the details of the rules of the game and the rules of safety of the players are explained and that the players understand these rules before starting to practice the sport of wrestling.

Ensure that there are experts and trainers with high efficiency and experience in the field of arm wrestling, always standing on the health of the players and making sure of their health condition constantly during training and matches.

Doing a periodic examination of the players before the start of tournaments or matches, as well as making a medical examination for the players before starting the sport of arm wrestling, and this thing is in order to preserve the safety of the players and to stand on their health conditions to avoid injuries and avoid pressure on any injury.

\section{CONCLUSION}

As we know that sport in general is an enjoyable and beneficial thing for the body, and we must practice it periodically in addition to that the sport that we are talking about currently, which is the sport of arm wrestling. Avoid falling into the injures and fractures, so it turns from an enjoyable sport, a beautiful thing that we practice, into pain, fractures and it cost treatment and loss of time, money, effort and health.

As the mental and physical preparation and the full study of the situation, rules and injuries related to this game is keep us away of all what we have talked about from injuries, pains, and it makes us enjoy what we do away from risks

\section{REFERENCES}

[1]. Low, B. and Lim, J. (n.d.). FRACTURE OF HUMERUS DURING ARMWRESTLING: REPORT OF 5 CASES. [Online] Available at: http://smj.sma.org.sg/3201/3201a7.pdf.

[2]. Correia, R. F., Ribeiro, A. N., \&Araújo, R. P. de. (2018). Arm-wrestling injuries A systematic review of the medical literature. Manual Therapy, Posturology\& Rehabilitation

Journal, 16 https://doi.org/10.17784/mtprehabjournal.2018.16.567

[3]. Correia, R.F., Ribeiro, A.N. and Araújo, R.P. de (2018). Arm-wrestling injuries A systematic review of the medical literature. Manual Therapy, Posturology\& Rehabilitation Journal, 16.

[4]. (n.d.). Arm Wrestling Rules: How To Arm Wrestle | Rules of Sport. [online] Available at: https://www.rulesofsport.com/sports/armwrestling.html [Accessed 3 Sep. 2020]. 